\title{
A system dynamics model for energy planning in Niger
}

\author{
Yacouba Moumouni ${ }^{1}$, Sajjad Ahmad ${ }^{2}$, R. Jacob Baker ${ }^{1}$ \\ ${ }^{1}$ Electrical and Computer Engineering, University of Nevada, Las Vegas, USA \\ ${ }^{2}$ Civil and Environmental Engineering and Construction, University of Nevada, Las Vegas, USA
}

Email address:

yacoubam@unlv.nevada.edu (Y. Moumouni), sajjad.ahmad@unlv.edu (S. Ahmad), r.jacob.baker@unlv.edu (R. J. Baker)

\section{To cite this article:}

Yacouba Moumouni, Sajjad Ahmad, R. Jacob Baker. A System Dynamics Model for Energy Planning in Niger. International Journal of Energy and Power Engineering. Vol. 3, No. 6, 2014, pp. 308-322. doi: 10.11648/j.ijepe.20140306.14

\begin{abstract}
This paper proposes an energy management model using system dynamics (SD) modeling approach. The time span of the model extends from 2003 to 2030. The Model was calibrated and used for the evaluation of six policy scenarios. Population, per capita electricity consumption, and the industrial sectors were identified as key components and used as inputs to predict future electricity supply and demand needs. Particular attention was paid, in the proposed model, to the individual and total amounts of carbon released into the atmosphere. Finally, to demonstrate the usefulness of the model, it was applied to Niger's electricity sector. The raw data from the past ten years was used as a benchmark for the study. A key factor in this study was Niger's fast growing population. The quick increase in population will add uncertainties to both the projections and the accuracy of the results. Model results show that by putting a particular emphasis on the national supply, Niger may be energy self-sufficient from 2018 through 2030. The model also indicates that the bond between Nigeria and Niger must be firmly restrengthened for the latter to be able to meet its future electricity challenges. The proposed model can be used in guiding public policy in developing regions.
\end{abstract}

Keywords: Energy Supply, Per Capita Electricity, Carbon Footprint, Niger, Population

\section{Introduction}

A good understanding of a sovereign country's energy consumption is important for the country's long term development of its economy. Therefore, planning and estimating the country's electricity needs should be given a high priority. These two major components provide a mechanism for balancing supply and demand at all times [1]. A reliable energy supply is an important component for economic achievement and needed for most aspects of social promotion, happiness, and security [1]. Developing nations need to be self-sufficient in terms of both food and energy in order to enjoy the benefits of modern life and a high standard of living. Hence, energy plays a central and crucial role for the sustainability and the improvement of the current level of living in developing regions. Energy has become so important to the communities in the developing countries that it directly affects the economies of the nations and has a tremendous impact on the environment [2].

La Société Nigérienne d'Electricité, NIGELEC is the utility company in charge of the generation, the transmission, and the distribution of electricity in Niger. Up to $95 \%$ of NIGELEC is controlled by the state government. Further,
NIGELEC has a monopoly over all matters related to power management in Niger [3]. Niger, as in other developing nations in sub-Saharan Africa, is constantly struggling to meet its daily energy demand and has been struggling since its creation as a sovereign country. Energy is a challenge in Niger because a long term energy solution has not been developed.

Furthermore, the understanding of this dynamic structure, along with investments that attempting to meet energy demands, will resolve the issues of frequent summer energy shortages in Niger as a whole and particularly in the Western part of the country that has a much higher load density. The total number of customers in 2010 was estimated to be 137,714 and out of that, 87,927 customers, i.e. $63.85 \%$ were located in the capital city of Niamey (Communauté Urbaine de Niamey, CUN). In other words, of the over $474 \mathrm{GWh}$ of energy sold in 2010, the city of Niamey purchased $331 \mathrm{GWh}$, thus making the electricity consumption in CUN roughly $70 \%$ of Niger's total energy usage [4]. Further, in 2000, the Ministry of housing estimated the number of additional homes to be developed in Niger at, around, 40,000 per annum [5]. These additional houses will further increase the demand for electrical energy in Niger and are factored into the model 
developed in this work.

To better understand the extent of the electricity problem in Niger, it is vital to start with the current status and trace back the historical aspects of energy supply and demand for the entire country. Hence, the main contributor to electricity supply in Niger is undoubtedly Nigeria. The supply from Nigeria was, approximately, a constant $40 \mathrm{MW}$ from 1976 to 2008. The transmission lines between Niger and Nigeria were upgraded in 2008 so that $80 \mathrm{MW}$ of power could be transmitted. This was needed to help supply the growing energy needs of Niger. Unfortunately, the attempted increase in transmission capacity failed. The renovated lines were only able to support $50 \mathrm{MW}$, falling short $30 \mathrm{MW}$. To date, Niger is importing more than $85 \%[6,7]$ of its energy from Nigeria. This energy dependence limits the ability of Niger to grow, develop, and improve the quality of life for its citizens.

In addition to the $85 \%$ of energy coming from Nigeria, located at Gamkale (Southern part of CUN) and Goudel (Western part CUN), are spinning reserve capacities. A Natural Gas (NG) turbine of $15.6 \mathrm{MW}$ is located at Gamkale and a Heavy Fueled Oil (HFO) fired plant with a capacity of $12 \mathrm{MW}$ is located at Goudel. These two generation facilities add a capacity of $27.6 \mathrm{MW}$.

The utility company divides the operations into Interconnected Zones, mainly: Northern Zone, Western Zone, and Central Zone. The Western Zone, which represents the main focus of this study, had its demand estimated at $20 \mathrm{MW}$ from 1976 up to 2004. Today the electricity demand in this same Zone is about four times bigger $(\sim 80 \mathrm{MW})$. It is also worthwhile to mention that the supply from Kanji Dam in Nigeria is highly dependent on rain fall, and at least two minimum criteria have to be met consistently for Niger to be able to harness the aforementioned $50 \mathrm{MW}$. These criteria are mainly a certain amount of rain fall per year within an acceptable range of 200 to $500 \mathrm{~mm}[8]$ and that the entire transmission system should work perfectly and have no failures. In addition, if the spinning reserve were to be turned on simultaneously, only 77.6 MW (97\%) of the Niger's needed power would be produced. This potential shortage has been a problem for more than a decade. The utility company deals with having more demand than supply, especially during the summer months, by shading down loads to avoid a major collapse of the entire system. Hypothetically, if any major damage were to happen on the interconnected line from Nigeria, and if all the spinning reserve were turned on, only, approximately, $29.5 \%$ of Niger's total demand could be supplied [6].

An important paradox worthy of note is that Niger has been exporting electricity to Malanville, Benin immediately across the Southern border. The amount of energy exported was estimated at $3.842 \mathrm{GWh} /$ year in 2011 [4].

The research objectives of this paper are to: 1) identify the major consumers of electricity in Niger and estimate how consumption changes over time, 2) apply a system dynamics, $\mathrm{SD}$, approach to model Niger's energy future, and the corresponding $\mathrm{CO}_{2}$ emission trends, and 3) identify Niger's potential dependence on energy imports as its population increases in order to ban frequent summer power outages in CUN.

An attempt will be made to answer the following three major questions: a) How energy demand will change in the future (by 2030) considering population growth and the number of homes having access to electricity?; b) How the Kandadji dam project will change the supply-demand balance in C.U.N.?; c) Can Niger be self-sufficient in terms of energy if the supply from Nigeria is jeopardized?

The following sub-section briefly reviews existing literature related to electricity supply and demand estimations. Section 2 explains the methodology and data collection utilized in this study. Section 3 presents and discusses the theoretical results. Finally, Section 4 concludes the paper by giving a summary of the study's main findings and their policy implications.

\subsection{Literature Review}

Approaches to estimating electrical energy supply and demand are varied. Through a careful review, the techniques can be broadly categorized into either general or specific methods. A further classification would be based on a country's energy supply and demand projections. The planning of an accurate estimate is of paramount importance not only in the design of effective energy policies, but also in utility management. This is because the electricity supply and demand must be maintained in a balanced condition for the power grid to be stable $[9,10]$.

\subsubsection{General Approaches}

Pioneering work in predicting energy supply and demand was done after the first oil crisis in the 1970s. This work was based on a mathematical model and it has been used to predict the US' electricity supply and demand [11]. Recently (2012), an optimized approach based on scheduling algorithms was formulated to solve three mataheuristic aggregated flexible scenarios [12]. These results demonstrated that a revolutionary algorithm can efficiently handle thousands of aggregated flexible inputs. In the same year, and in light of the Fukushima nuclear disaster, three proposed electricity policy scenarios for 2030 were offered to quantitatively estimate future Japanese electrical energy consumption [13]. The focus was in terms of nuclear power and the subsequent renewable energy (RE) penetration.

Although not much research has been done in the developing regions, there are a few interesting studies. The present and future potential of the electricity sector in Saudi Arabia with emphasis on RE penetration was investigated in 2005 [14]. Two years later, the South African electricity sector with a partial equilibrium energy-environmenteconomic (E3) modeling approach was investigated, where not only a stochastic method was utilized, but also all the aspects of flexibility to demand growth uncertainties were considered as well [15]. An electricity Supply Curve Bidding (SCB) approach was presented in order to investigate customers' demand functions at load busses, and network capabilities [16]. Though this paper treats aspects related to 
electricity supply in a developing country (Jordan), it is important to note here that the SCB approach utilized works in conjunctions with both the market-clearing and the power network settings. In 2011, a comprehensive article detailing recent energy trends in Vietnam was provided along with supply and demand projections for years to come [17].

It is worthy of noting that despite the lack of equivalent studies within emerging economies, and sub-Saharan African entities in particular, an Autoregressive Distributed Lag (ARDL) approach has been employed in their respective work in order to estimate residential and aggregate electricity demand in Namibia and South Africa correspondingly $[18,19]$. As a final review in 2012, a study was conducted in Ghana based on the ARDL bounds co-integration approach [20]. They mainly attempted to identify the drivers responsible for the aggregated domestic electricity demand growth and their effects on the short and long run.

\subsubsection{Specific Approaches}

In the course of this research it was found that the existing approaches, based on system dynamics (SD) modeling techniques, frequently use either: 1) econometric or 2) enduse accounting to model energy dynamics [15].

One of the originators of SD's application is Naill [21]. He modeled the US gas industry by means of this novel tool in 1973. Nearly a decade later, Sterman performed a systematic analysis utilizing SD in order to investigate the mutual behavior between the economy and energy sectors [22]. These conceptual planning schemes were not only predicted accurately, but were also encouraging to the research community. They fit exactly in their particular scopes, but had paid less attention to the energy supply and demand in developing regions. Despite SD being concisely demonstrated to be one of the best approaches in energy supply and demand planning, few research efforts have been done using SD techniques [23]. On the other hand, it is documented that the aftermath of the first energy crisis not only grabbed the attention of the lawmakers and the scientists, but was intensively followed by an increasing amount of research work in the field of energy supply and demand in the developed world [24].

It is worthy to point out that Rahn [25] followed by Ford [26] were the first to attempt to apply SD in electricity demand prediction. Recently, an SD approach was utilized to model the Canadian power system in order to investigate ways to achieve a sustainable and balanced electricity supply and demand [27]. This model tracks and investigates the Western electricity demand and supply patterns which can be accurately estimated ahead of time due the abundance and availability of data on consumers.

On the other hand, in 2001 an SD theory was used to investigate the dynamics of electricity supply, resources, and pollution in Pakistan [28]. A few years later, the entire Indonesian energy sector was simulated using SD with emphasis on the security and the percent of energy imported and its dependence [29]. Additionally, a feedback mechanism was utilized in SD theory to project Hebei energy consumption and demand characteristics [1]. In their analysis they did use various variables such as economic growth and population to understand the inter-dependencies when projecting Hebei future energy trends. Afterward, two successive, but slightly different papers were published in 2012 by the same authors. In the first paper [30], an SD model was developed utilizing population and per capita electricity in order to estimate the future electricity consumption in Indonesia. But the model was too compact and failed to capture the contribution of the various electricity production sectors. This failure was mainly due to the fact that, they aggregated the entire production mix as one single unit which turned out to be hard to decipher in terms of conventional and or renewable sources. The second was more comprehensive although it was based on the same two aforementioned variables. They first pointed out the importance of anticipating the electricity supply and demand to both the lawmakers and the general public [31].

Hence, most of the research, to date, in the field of energy projection has been done in the developed countries. Some of the fundamental reasons are that their systems are well documented and most importantly there are many grants allocated to carry out comprehensive research. Less research has been done in the rest of the world in the field of energy and much less in Niger which is considered one of the poorest countries in the world [32]. In this regards, the authors are unaware of any work that has attempted to comprehensively model the energy and/or electricity sector in Niger. Therefore, this paper seeks to bridge the existing gap by identifying the major contributors in terms of electricity consumption and models Niger's energy future by quantifying its dependence on energy imports as population increases.

\section{Methods}

\subsection{An Overview of SD Modeling Approach}
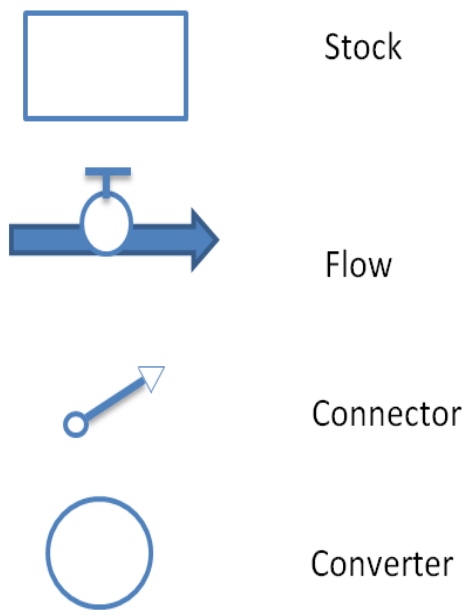

Figure 1. SD models building blocks.

System dynamics (SD) is a computer simulation and modeling approach to understand the behavior of 
complex systems over time [33-35]. Distinguishing characteristics of this approach include incorporation of material and information delays and feedback loops [36, 37]. The approach was developed by Professor Jay Forrester at Massachusetts Institute of Technology in mid 1950s. Theoretical background and details of system dynamics modeling approach can be found in Sterman [38]. System dynamics models are developed using four basic building blocks called stocks, flows, connectors and converters as depicted in the Fig 1. The stock represents an accumulation or depletion of either tangible or non-tangible variable such as population or belief. Stocks can only change through flows into or out of a stock. Converters are used to house data or mathematical relations, and connectors are used to link stocks, flows, and converters [39, 40]. The ordinary differential equations describing system dynamics models are solved using finite difference schemes. SD models can be used for planning, evaluation, what-if type scenario analysis, and decision support [41-48].

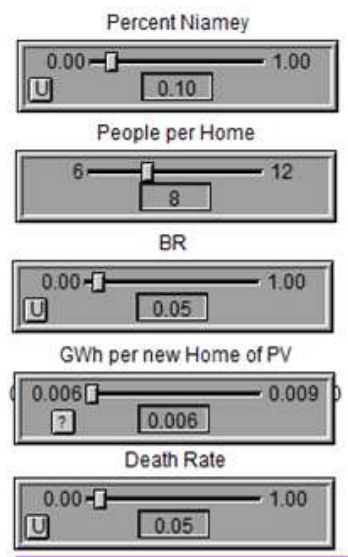

Brief summary on how to use the Gragpical User Interface (GUI)

1.The Kandadji Dam is currently under construction and will only contribute once it is over in the horizon of 2018. The projected Capacity is $629 \mathrm{GWh}$ on a yearly basis.

2. We have considered three different scenarios and their various combinations.

2a. The birth rate which is a key factor can be switched between the default value, i.e. 0.0461 and a new value of 0.02 set that should be greater than the Death Rate (DR)

2b. Summer season is given a ON and OFF status, i.e. 0 or 1 because the aim is to ban power outages in Niamey by means of additional renewable sources that could be turn automatically oN to meet the peacks.

$2 c$. Finally the PV installed on the newly constructed homes is allowed to vary between the actual value $(6.2 \mathrm{KWh})$ and a new value of $9 \mathrm{KWh}$ that is considered to fit the newly constructed homes as life goes on due to the fast growing acquisition of the newly advanced technological devices.

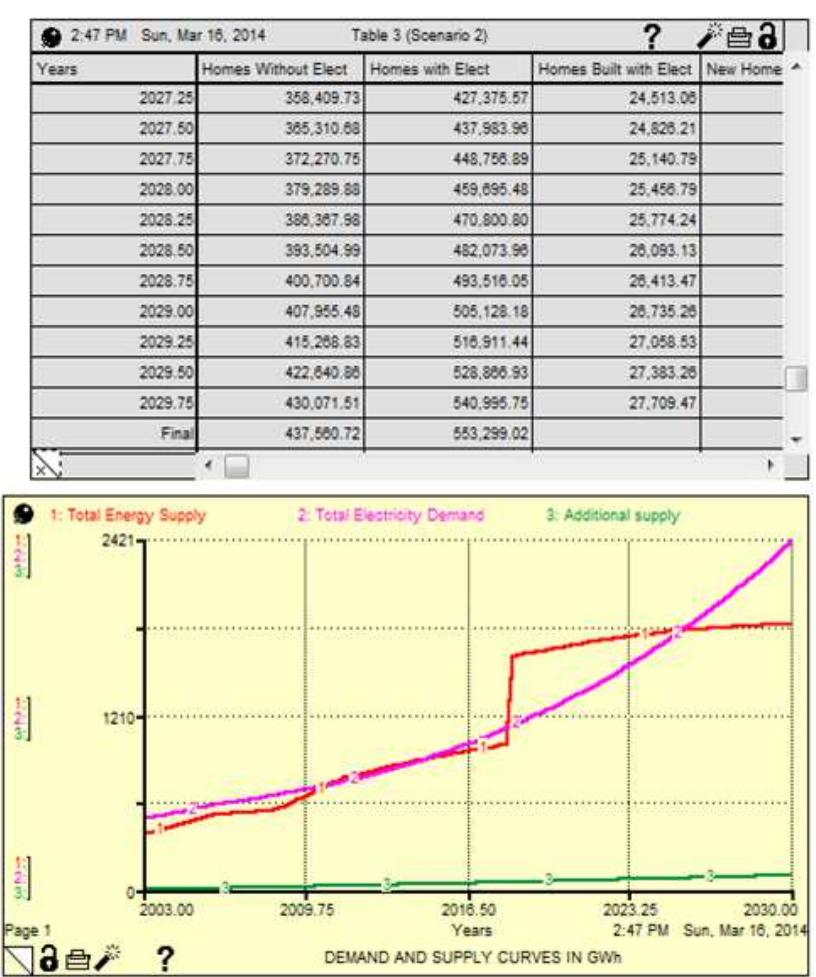

Figure 2. GUI level of the model in ithink.

\subsection{Model Interface}

A friendly graphical user interface (GUI) is provided (Fig. 2) for policy testing and formulation using the ithink software [49]. A brief description of how to use the GUI is also included in this figure where the user can input the required data using sliders, tables, and switch input devices. This allows the user to quickly alter values of various parameters to conduct 'what if' analysis without the need to make changes at the structural level. Results are displayed graphically and/or stored in tabular format for analysis. The additional functionalities give the user the privilege to run, pause, or resume a simulation.

\subsection{Data}

In order to develop this model, the study relied mostly on the energy data presented in [4] as it is one of the major and most reliable sources of energy information about Niger. These data range from 2003 to 2012. Other data were selected to follow the available energy data. Hence, the annual per capita consumption of electricity in Niger in the year 2011 was estimated at $35 \mathrm{kWh}$. In 2006 only $9 \%$ of the population $[4,7]$ had access to electricity. In the years that followed 2006 a large campaign of rural and sub-urban electrification was carried out by the authorities. The result is that the current population having access to electrical energy is estimated at $22 \%$ [7]. The annual rate of the increase in people getting access to the electricity supply is estimated to be about $2.5 \%$ [50]. An important factor that has a significant impact on the outcomes of this study is the population of the country, which is estimated at around 17 million inhabitants in the year 2012. The associated birth and death rates are 46.1 and 11.6 per thousand people respectively. The future housing demand is estimated at about 40,000 per annum in Niger. Also, the urban population is estimated to double every 12 years [5]. Note that of the aforementioned population, CUN has only around a million inhabitants, i.e., $5.8 \%$ of Niger's total population [4] and yet its energy demand is tremendously increasing. This concentration of electrical load in CUN has a negative effect on the availability of the utility service specifically, during the 
summertime. Table 1 lists the most important data sources utilized in this study.

Table 1. Data and sources.

\begin{tabular}{|c|c|c|}
\hline Variables & Values & References \\
\hline Total population & $17,129,076$ & [4] \\
\hline $\mathrm{BR}$ and $\mathrm{DR}$ & $\begin{array}{l}0.0461 \\
0.0116\end{array}$ & [4] \\
\hline Population in Niamey & $1,011,227$ & [4] \\
\hline Per capita Electricity & $35 \mathrm{KWh}$ & {$[4,7]$} \\
\hline$\%$ of population having electricity in 2006 & $9 \%$ & {$[4,7]$} \\
\hline$\%$ of population having electricity in 2013 & $22 \%$ & {$[4,7]$} \\
\hline Electricity per economic sector & (See Table 2) & {$[4,7]$} \\
\hline$\%$ of electricity import & $85 \%$ & {$[4,7]$} \\
\hline$\%$ of electricity export & $0.3 \%$ & {$[4,7]$} \\
\hline Annual rate increase of electrification & $2.5 \%$ & {$[50]$} \\
\hline Utility company's local power generation & $27.2 \mathrm{MW}$ & {$[6,7]$} \\
\hline Solar thermal power capacity & $10 \mathrm{MW}$ & {$[51]$} \\
\hline Dam Kandadji's annual capacity & $125 \mathrm{GW}$ & {$[6,7,52]$} \\
\hline Average fecundity rate & 7.1 to 7.6 & {$[4,52]$} \\
\hline
\end{tabular}

\subsection{Energy Sectors}

Table 2. Electricity consumption per sector

\begin{tabular}{lllllll}
\hline Sectors & \multicolumn{7}{l}{ Years/Values (GWh/year) } \\
\hline Low Voltage & 2006 & 2007 & 2008 & 2009 & 2010 & 2011 \\
Household/private & 215 & 243.5 & 270 & 304 & 338.2 & 366.5 \\
Government & 14 & 15 & 15 & 20 & 19 & 23 \\
Total1 & 229 & 258.5 & 285 & 324 & 357.2 & 389.5 \\
Medium Voltage & & & & & & \\
Business/private & 33.5 & 12.72 & 14.1 & 39.8 & 56.9 & 45.9 \\
Industries & 38.8 & 89.3 & 84.2 & 52 & 50 & 45.6 \\
Government & 29.2 & 47.5 & 36.3 & 43 & 35.3 & 2.1 \\
Agriculture/Irrigation & 14 & 5.7 & 6.1 & 6 & 5.3 & 5.5 \\
Total2 & 115.5 & 155.2 & 140.7 & 140.8 & 147.5 & 99.1 \\
Export (Malanville) & - & - & 2.489 & 0 & 2.377 & 3.842 \\
Total Consumption & 344.5 & 413.7 & 428.2 & 464.8 & 474.1 & 492.4 \\
Niamey (CUN) & 245.3 & 257 & 277 & 285 & 331 & 325 \\
CUN Consumption & 71.2 & 62.12 & 64.7 & 61.32 & 70 & 66 \\
(\%) & & & & & &
\end{tabular}

The model was based on three factors: economic sectors, the population, and the per capita consumption of electricity for both conventional power and renewable alternatives for the past 10 years and the upcoming 20 years. It is worthy of note that a clear distinction was made in the demand for the different sectors of the economy on the premise that breakdown was required at a strategic level. The details are in Sec.2.4.1. Table 2 elucidates the year round electricity consumption per economic sectors. It should also be noted that this model is just for demonstration purposes and is not fully deemed ready for utility management decisions.

As already mentioned, $63.85 \%$ of the power in Niger was consumed in Niamey. Therefore, as a direct consequence, power is neither sufficient, nor present at all times to the devoted customers. This has a more severe negative impact on the national economy due to the fact that daily affairs might be paralyzed by the absence of electricity. Therefore, there is a loss in business profits at individual as well as societal levels. The energy issue is a great deal in Niger because it counts on foreign supply to satisfy the daily electrical needs.

Hence, the purpose of this paper is twofold. First, investigate the future trends of the national supply and demand of electricity after the Kandadji dam is completed. Second, to investigate what would be the impact, or the benefit, of continuously having an electrical energy supply from Nigeria and how the latter would evolve and be compared to the former? The system dynamics model proposed in this study is comprised of many stocks, flows, and auxiliary variables. The major stocks, the feedbacks, and other interconnections among the stocks and the variables of the model are described in Secs.2.4.1 through 2.4.4. Some key sensitive strategies and assumptions are presented below as effective policy scenarios in order to investigate ways to resolve the issues of electrical power outages in Niamey in the years to come. Figure 3 depicts the map of the study area known as Western Zone in the red square.

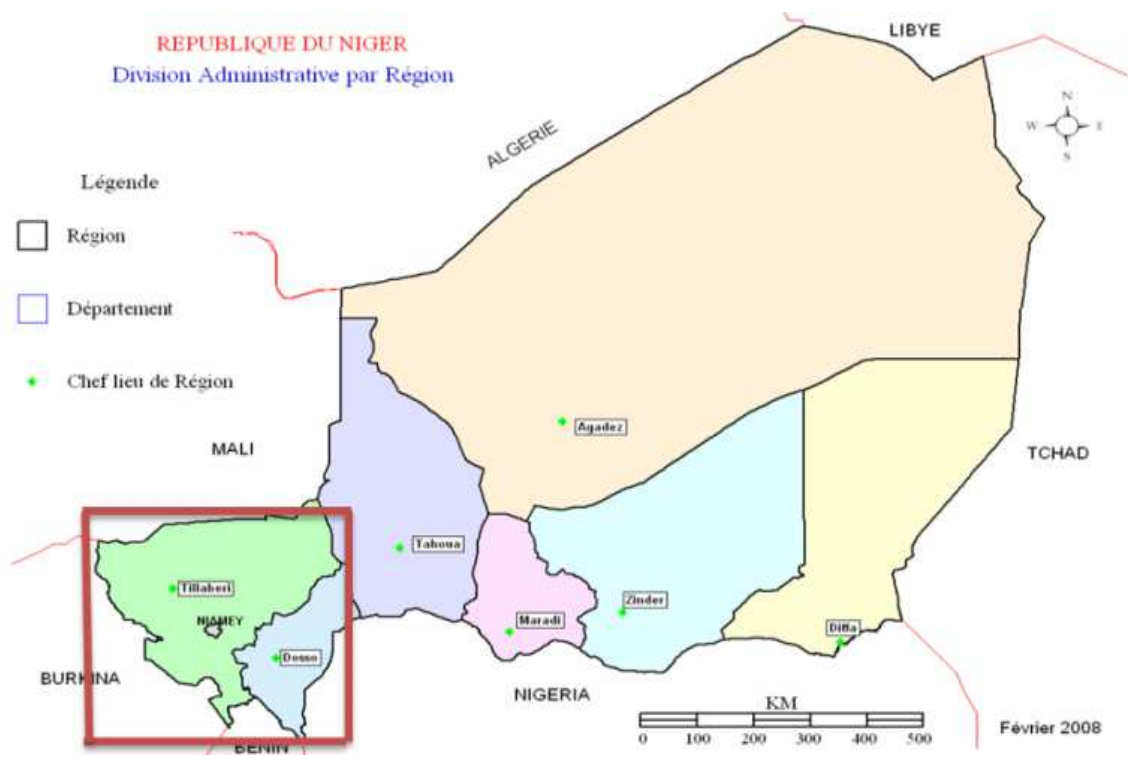

Figure 3. Map of the study area [53]. 
The proposed model is used to explore:

a) How fast the energy demand is changing as the population dramatically increases.

b) The effect of Kandadji dam (nominal annual capacity of $629 \mathrm{GWh}$ ), which is under construction, in the national supply mix. The dam will be fully operational in the horizon of 2018 and will constitute the major input from the national supply side.

c) Other contributors, the emerging renewable technologies, i.e. photovoltaic, PV, and concentrated photovoltaic, $\mathrm{CPV}$, as valuable alternatives to alleviate the ever growing demand.

d) Finally, the individual and the total carbon footprint, CFP, of the various sources of electricity in Niger.

\subsubsection{Demand Sector}

The demand sector estimates the electricity demand and use during the entire simulation period for the fast growing population. The average annually household consumption is determined using the per capita demand and the number of people per house. Moreover, the demand sector includes the major contributors in terms of electricity consumption. Population is one of the major driving forces behind the amount of electricity demand in the country through the domestic consumption. It also governs partly the various sectors of demand such as commercial, industrial, and agriculture. The total electricity demand consequently depends entirely upon population and the level of the economic growth in the country. Therefore, in this study, a particular emphasis was put on the two dominant factors, i.e. population and the agro-industrial sectors. Below is the list of the major variables:

- Population

- Industry

- Agriculture

- Transport, and

- Government and Others.

Note that the population is divided into existing and new population. These two components can further be categorized into two broad groups with the help of the number of occupants per household: existing homes with and without electricity, and new homes with and without electricity. So, the re-enforcing loop generated here would be that as population increases faster, the number of homes built in Niamey and surrounding vicinity will grow likewise. Therefore, the electricity demand will keep increasing at the same rate. Consequently, demand change is a function of the number of existing homes with electricity and the new homes that will have access to electricity in the long run. In addition, the demand will also increase as the existing and new homes without electricity change status by being electrified.

It is also crucial to point out that the economic sector, as a whole, is the second contributor in terms of energy demand in Niger. There is a clear tendency that this sector is increasing as portrayed in $[4,32]$ due to some newly discovered resources that are being exploited in the country, and the popularity of the electronic gadgets in the cities. In short, the second most important self-re-enforcing loop is that the population growth will result in an increase in the work force, which in turn will improve the national economy.

Finally, a great measure of understanding how well the total electricity consumption is related to the total supply is quantified in this study and called the "Electricity Gap." The latter is a subtraction between the demand and supply sectors. Consequently, there are three different outcomes. First, the gap can be positive through the entire simulation period. Second, the gap is sometimes marginal, i.e. the supply exactly matches the energy consumption. Lastly, the gap turned out to be negative under certain policy scenarios. A comprehensive analysis of these statements is carried out in the results and analysis section.

\subsubsection{Supply Sector}

Various sources, both conventional and renewable, are considered in this study. Not all of these sources play a fundamental role at a national level. Nevertheless, summing up those infinitesimal and disperse sources of power will result in a significant compound source that would certainly help in cutting down the load. Again, however, the major contributors are the dam Kandadji under construction, the coal fired plant (Anou Araren) and the imported electrical energy from Nigeria.

\subsubsection{Carbon Footprint Sector}

Carbon dioxide $\left(\mathrm{CO}_{2}\right)$ is one of the dominants greenhouse gases (GHG) that leads to climatic change and global warming. $\mathrm{CO}_{2}$ concentrations are increasing above preindustrial levels [54]. CFP is an all-encompassing term for pollutants. The term is therefore shorthand to describe not only in an understandable manner, but also in the best estimable sense what can be gotten of the full climate change impact of that pollutant [55]. As stated above, the major and most prevalent sources of energy are fossil-fuelled based. Therefore, GHG emissions from burning fossil fuels are heavy of consequences on every living being on Earth. The effects will be more noticeable in the years to come. Hence, the challenges are multiple, ranging from depletion of fossil fuel reserves to a significant fuel price rise in the World. This situation is certainly less desirable for mankind in particular and depicts an energy consumption trend that is rather unsustainable. Fortunately, as energy consumption is growing bigger, emerging renewable technologies are under development [56]. The aforementioned alternatives are the way out to the current energy issues and/or the future challenging ones. Nevertheless, even these "so-called" clean and renewable technologies do emit some pollutants into the environment. Therefore, the individual and total equivalent metric tons of $\mathrm{CO}_{2}$ per every GWh of energy produced during the course of their lifecycle are quantified in this study. The individual lifecycle GHG emission intensity per energy source was reported in [57]. An emphasis is put on the degree of cleanness of the national utility company. The company has a Natural Gas (NG) energy production capacity of 15.6 
MW which corresponds to $56.52 \%$ and a HFO fired power plant capacity of $12 \mathrm{MW}$ of the remaining percentage, i.e. $43.48 \%[7]$.

\subsubsection{National supply and Import Sector}

This sector is mainly for comparison purposes. The important factors to note in this sub-section are the total energy supply, the supply without taking into consideration the energy imported from Nigeria, and finally the ratio of the national energy supply to the imported energy from Nigeria.

\subsubsection{Mathematical Formulations}

The pertinent mathematical functions to the long term electricity needs in Niger are presented in this section.

- Population

The inflows to the "population" consist of births while deaths are considered as the outflows, i.e. the decreasing or balancing factor from the "population". Therefore, the population based on the above mentioned dynamics at any instant ( $\mathrm{t}$ ) can be estimated utilizing (1).

$$
P(t)=P(t-d t)+(\text { NetBirth }- \text { NetDeath }) \cdot d t
$$

where,

$P(t)$ is Population at time, ' $t$ ',

$P(t-d t)$ is Population at previous time step,

Net Birth is the number of births in time, $d t$, and

Net Death is the number of death in time, $d t$.

- New population

It is very imperative to not just accurately model the existing population, but also to be able to model the new population during the upcoming years. This will enable us to project, as accurately as possible, the future electricity consumption in Niamey. This new population is estimated through (2).

\section{NewPopulation $=$ Population - InitialPopulation}

Where,

New population is the future population, and Initial population is population at the current time, $t$.

- Domestic demand $(D D)$

Additionally, the electricity demand per household is equivalent to the per capita electricity used times the number of family members. Hence, it is important to note at this point that the national average fecundity rate is estimated at 7.1 children [4, 52]. So, for simplicity purposes, it is considered an average number of 8 persons per household in CUN for this model which is in compliance with the above sources. Also, per capita demand is another socio-economic factor that drives the total electricity demand in this model in addition to the economic sectors. The total domestic electricity consumption is calculated based on the historic trend of the per capita demand. Equation (3) is the mathematical formulation of it.

$$
D D=H o w E l \cdot \text { Percap Demand } \cdot \text { Pph } \cdot \text { Constant }
$$

Where,
$D D$ is total household electricity consumption,

HowEl (Homes with Elect) is total homes having access to electricity,

Percap (Per capita) Demand is the electricity consumption per person/day,

Pph (People per home) is the number of people per household, and

Constant is just a multiplication factor that takes care of the conversion from $\mathrm{kWh}$ to GWh.

- Homes with electricity (HowEl)

Although Niamey resembles all the modern cities in West Africa, not all the houses have access to electricity. Equation (4) below quantify this variable.

$$
\operatorname{HowEl}(t)=\operatorname{HowEl}(t-d t)+(H B w E l+H a E l) \cdot d t
$$

Where,

$\mathrm{HowEl}(t)$ is homes with electricity at time, t.

HowEl $(t-d t)$ is homes with electricity at previous time step,

$H B w E l$ (Homes Built with Elect) is the new homes built that have access to electricity, and

HaEL (Percent of Homes to access Elect) is the percentage of homes without electricity that access it as time goes by.

- Total electricity demand (TED)

This section depicts the overall demand the study is attempting to estimate and meet through some policy scenarios. It represents the summation of the individual demand of the various socio-economic sectors in the capital city and its surroundings as shown in (5).

$$
T E D=A D+D D+I D+T D+T r D+(P S \text { and } \mathrm{O} D)
$$

Where,

$A D$ (Agric Demand) is the agricultural electricity demand,

$D D$ (Domestic Demand) is the total domestic demand,

$I D$ (Industrial Demand) is the total industrial demand,

$T D$ (Tertiary Demand) is the total tertiary demand,

$\operatorname{Tr} D$ (Transportation Demand) is the total transportation system electricity consumption,

$P S \& O D$ (Public Sector and Other Demand) is the government and other businesses' electricity demand.

- Total electricity supply (TES)

Like the previous section, the total supply, (6), represents all the supply mix available currently in Niger including some newly additional alternative ways that could be considered in a near future in order to ban the frequent summer power outages in Niamey.

$$
T E S=(A S+C P+E P V+\text { Nigelec }+D K+I) \cdot(100 \%-P E)(6)
$$

Where,

$A S$ (Additional Supply) is $10 \mathrm{MW}$ solar thermal plant and $\mathrm{PV}$ installed on the new homes,

$C P$ (Coal Plant) is $37.7 \mathrm{MW}$ thermal plant installed in the Saharan Desert at Anou Araren,

$E P V$ (Existing PV) is the current installed PV capacity in Niger, 
Nigelec represents the NG and HFO capacity of the utility company,

$D K$ (Dam Kandadji) is the $125 \mathrm{MW}$ Dam under construction near Niamey,

$I$ (Import) is the $85 \%$ supply from Nigeria, and

$100 \%-P E$ (Percent Export) is the $0.3 \%$ export to Benin.

- Total carbon footprint (TCFP)

The total CFP, (7), represents the summation of the individual aforementioned power plant's GHG emission into the environment either directly or through other means. This is regarded as a lifecycle rejection and may sometimes be tremendous even for the renewable alternatives that supposedly are meant to cut down carbon emissions.

$$
T C F P=(C+P V+K+K a+S T+E P V+T N) \cdot C F P
$$

Where,

TCFP stands for Total Carbon Footprint,

$C$ stands for Coal, $k$ stands for kanji Dam (Nigeria), $K a$ stands for Kandadji Dam (Niger), ST stands for Solar Thermal, EPV [see (6)], and $T N$ stands for Total Nigelec.

- Kandadji dam

Equation (8) is the representation of what the Dam under construction would contribute to the electricity supply composition in Niger. This equation is a conditional statement.

$$
\text { If time }>2018 \operatorname{HEN}(629 M W h) \operatorname{ELSE}(0)
$$

\subsection{Policy Scenarios}

To better understand the dynamics of electricity supply and demand capacity of the Western part of Niger, an SD simulation model was developed and validated to evaluate six different policy scenarios, as given in Table 3. Among those scenarios are four parameters that turned out to be critical, decisive, and inevitably important for Niger to attain self-sufficiency in terms of energy. The first is the birth rate (BR), which needs to be controlled or adjusted accordingly within the limits of the scares resources of the country and customs. The second is that, Niger needs to have by all means more RE in its energy generation mix. Third, Niger must increase its spinning reserve in order to meet the unpredictable summertime peaks in Niamey. Lastly, on top of all, the Kandadji dam under construction needs to be fully operational on the horizon of 2018 for Niger to aspire to selfsufficiency in terms of power in a near future.

\section{Results and Analysis}

\subsection{Supply and Demand}

Figure 4 depicts the past and current trends between the electricity supply and demand in Niger for both actual and simulated data. This discrepancy started back in 2003 with more homes having access to electricity. The increase in the number of homes receiving electricity has been the status quo for almost a decade now. The real curves serve as a benchmark for this study. As can be seen, depending on the national energy solutions adopted, the real supply fluctuated in time and space, but never did it intersect the real load. This explained the frequent power shortages in Niger during the last decade or so. Evaluation of model performance during calibration shows (Fig. 4) that model was able to reproduce historic supply and demand with maximum errors less than $7.1 \%$ and $6.2 \%$, respectively.

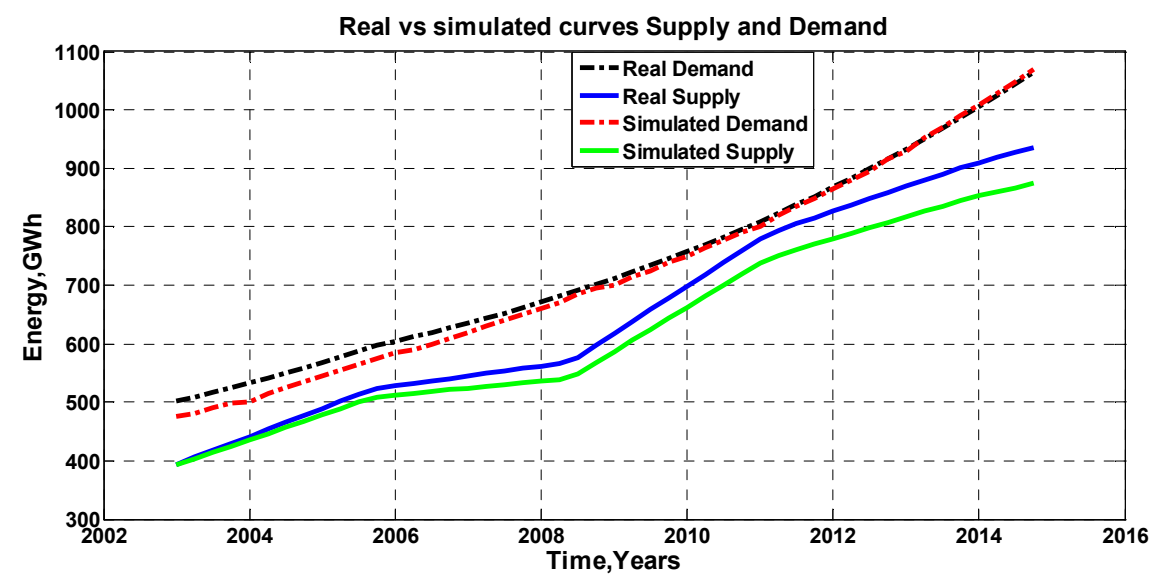

Figure 4. Electricity Supply and demand curves behavior utilizing past and simulated data

Table 3. Summary of the policy scenarios

\begin{tabular}{lllll}
\hline Scenarios & BR (\%) & Additional Supply & Dam Kandadji & PV per new homes (Kwh) \\
\hline 1 & 46.1 (Base case) & Off & 629 GWh in 2018 & 0.0 \\
2 & 20.0 (New) & Off & 629 GWh in 2018 & 0.0 \\
3 & 46.1 & On & 629 GWh in 2018 & 6.2 (Base case) \\
4 & 46.1 & On & 629 GWh in 2018 & 9.0 (New) \\
5 & 20.0 & On & 629 GWh in 2018 & 9.0 \\
6 & 20.0 & On & 629 GWh in 2018 & 6.2 \\
\hline
\end{tabular}




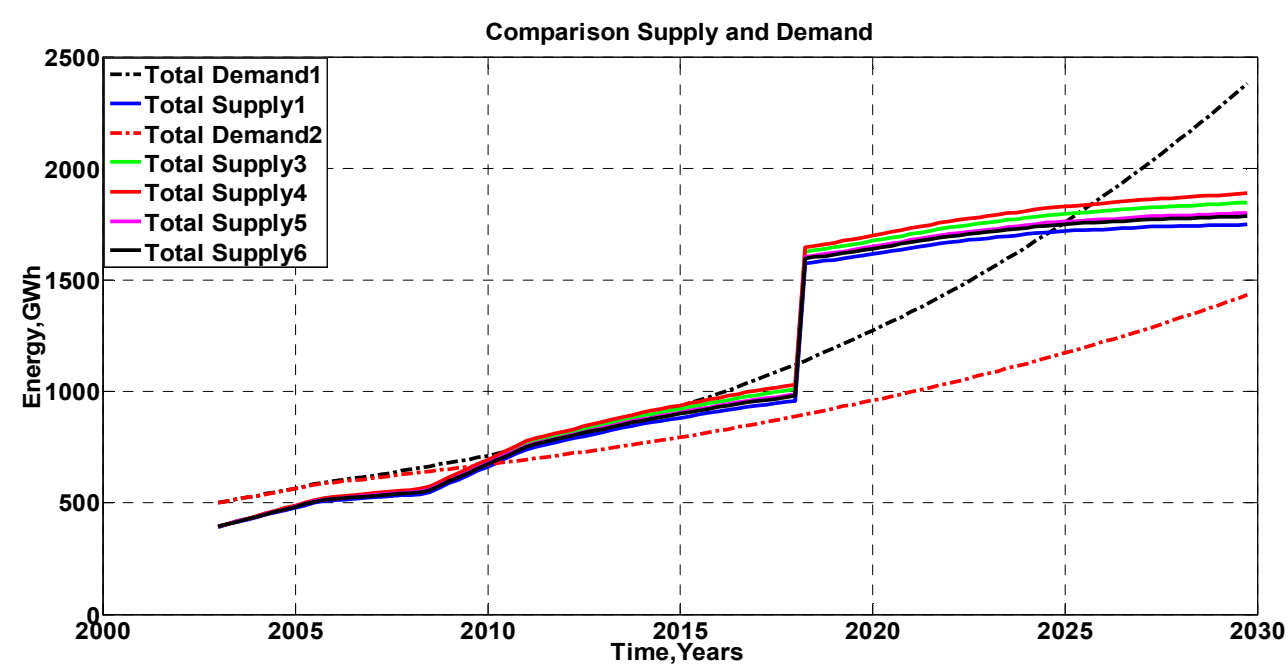

Figure 5. Demand and Supply projections.

Figure 5 on the other hand, shows the simulation results of all the scenarios for a better view and simplicity of comparisons; the supply and demand are the variables. They intersect in time at various locations. The dotted black line shows the total electricity demand under scenario one. It is worthy of note to point out that the total electricity demand under policy 1,3 , and 4 are all the same. So, only total demand 1 is shown for simplicity purposes. Likewise, total electricity demand under policy 2, 5, and 6 are all similar. For same above reason, only total demand 2 is shown in dashdotted red line. Finally, on the supply side, total supply 1 and 2 followed the same exact pattern. Hence, simply the former is shown in the solid blue line.

The solid blue line shows the total supply1 under the base scenario over the 30 years simulation period. At the end of this period, the total supply will be $1750 \mathrm{GWh}$. It can clearly be seen that once the $629 \mathrm{GWh}$ dam is built, there will be a significant boost in the national supply for all the scenarios. This is seen by the fact that the overall production jumped from $958 \mathrm{GWh}$ in 2018 to $1575 \mathrm{GWh}$ in the same year. Nevertheless, the dam itself, under this scenario, will not suffice for long term energy needs because the curve will just collapse after roughly seven successful years due to the alarming population growth. This fact is depicted through the intersection of supply and demand curves in 2024. Consequently, the import from Nigeria will continue to play a major role in the base case.

The second scenario involves halving the BR and everything else remains unchanged. Total demand 2 is shown in the dash-dotted red line whereas the total supply2 is as stated above same as in the first scenario (solid blue line). These two curves show no intersection over the 20 year period. Consequently, the import from Nigeria will continue to become less important and may start to decrease right after 2018. There is a clear difference between the base and the second scenarios. The population due to a net decrease in the BR is estimated to lessen by approximately 7 million people by 2030 as compared to the base case (see Table 5). This scenario is less probable to happen in Niger under the current birth control policies.

The solid green line shows the total supply3 corresponding to the third scenario. Demand and supply curves (black dotted and green respectively) intersect in late 2025. Having turned the additional renewable supply on, this scenario is an improved version of the base case. Although the demands are the same, this case supplies more than $97 \mathrm{GWh}$ to the nation due to the renewable integration to the grid. Not only would RE help to reduce down power bills, but will also help in alleviating the overall summertime power outages. One thing worthy of note is that the utility company needs to strengthen their spinning reserve in order to meet summer peaks because not everybody can afford RE sources, like PVs, due to higher initial cost and a longer pay back period. In short, the electricity import will continue to be an important component to the energy composition of Niger.

The solid red line shows the total supply4 which portrays the fourth scenario. The latter gave the best contribution in terms of overall supply with a capacity of $1888 \mathrm{GWh}$ at the end of the simulation period. The installed PV capacity per new home was increased to $9 \mathrm{kWh}$. As can be predicted, the supply and demand intersection is further pushed away in the future, i.e. 2026 (the red and black dotted lines). The drawback of this scenario is the financial burden on the society rather than the utility company. This is something the utility management would want, but again Niger is one of the poorest countries in the World [32]. Therefore this would not happen in a near future unless a major economical breakthrough or a second uranium boom occurs in the country.

The solid pink line shows the total supply5 as a result of the fifth scenario. There is zero intersection between the total supply and demand graphs over the period of 20 years and some years beyond (the pink and dotted red lines). Consequently, under this scenario Niger would have a surplus of $353.6 \mathrm{GWh}$ in 2030 as can be read from Table 5. This is a clear indication that not only the electricity import will continue to decline, but also Niger would be exporting electricity surplus. This scenario is one of the best in terms of 
how to quickly solve the energy issues in Niger for decades to come, but it is also of the most unlikely ones to occur (Population decrease is unsustainable). Less people, meaning less demand, additional supply resulting in a healthier economy. In this scenario every new home owner could afford both the national supply and the renewable sources.

Similar to the previous scenario, this last one is also under the seal of utopia with a minor difference, i.e. the PV installed per new home is solely based on the existing capacity. The solid black line shows the total supply6. The demand and supply curves with nil intersection over the period and beyond are depicted through the solid black and the dotted red lines. But electricity surplus has decreased by $14 \mathrm{GWh}$ as compared to the previous quantity.

\subsection{National Supplies and Import}

Figure 6 shows the various scenarios based on the national supplies and the electricity import from Nigeria over the 30 years period. Independent of the scenarios, the import is shown in the blue dotted-line. It is important to note that the national supply under scenarios one and two exhibited the same exact behavior. So, for the sake of simplicity only the latter supply is illustrated in solid blue line. Hence, as can be seen from the dotted and the solid blue lines, there is a distinct prevalence of the import over the national supply under these two policy scenarios. The hidden economical implication is that Niger, shortly after the completion of the Kandadji dam, will still count on import to meet its daily energy consumption.

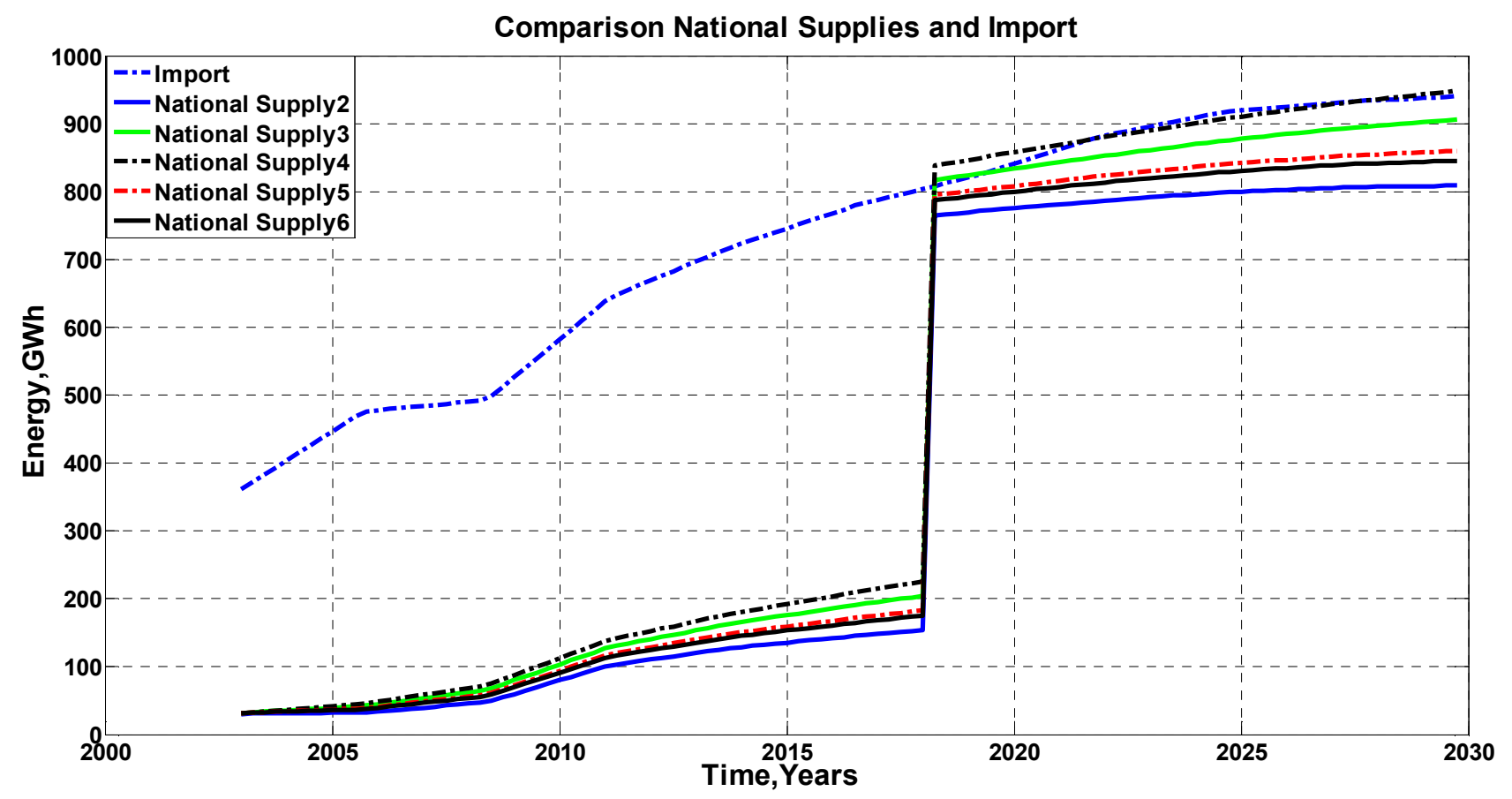

Figure 6. National supplies and Energy import projections.

Scenario three showed some sort of improvement as compared to the previous two cases. The green solid line shows the national supply3 over the 30 years of the simulation period. The national supply is comparable to the import for the first three years after the completion of the dam and then the import share takes over for the rest of the period.

The black-dotted line shows the national supply4. It dominates the import from 2018 up to 2021 then they both remain comparable to each another the remaining nine years. The dotted-red line shows the national supply5. This scenario clearly demonstrates that the import exceeds the national share by $81 \mathrm{GWh}$ at the end of the 30 years period.

The solid black line shows the national supply6 quite similar to the previous. Under this policy, the import exceeds the national electricity production by $95 \mathrm{GWh}$ instead at the end.

In a nutshell, with the alarming growing energy demand due to over population in the capital city, the status quo will continue to prevail even with the dam fully operational in the horizon of 2018. Niger, based on these policy scenarios, won't meet its internal electricity consumption in the years to come without a firm reliance on imported energy (up to 50\%). Hence, the country will need to invest either in RE, Nuclear or other types of economical and environmentally friendly sources in order to conquer its energy independence.

\subsection{Existing and New Homes}

Figure 7 shows the current and future electrification trends through the existing and new homes. The dramatic increase in population causes the number of homes having access to electricity to increase as well. The number of newly constructed homes with electricity also increases, but at a much slower rate. Based on these scenarios, a certain similar trends had emerged. Therefore, table 4 summarizes both new and existing homes that exhibited identical pattern. 


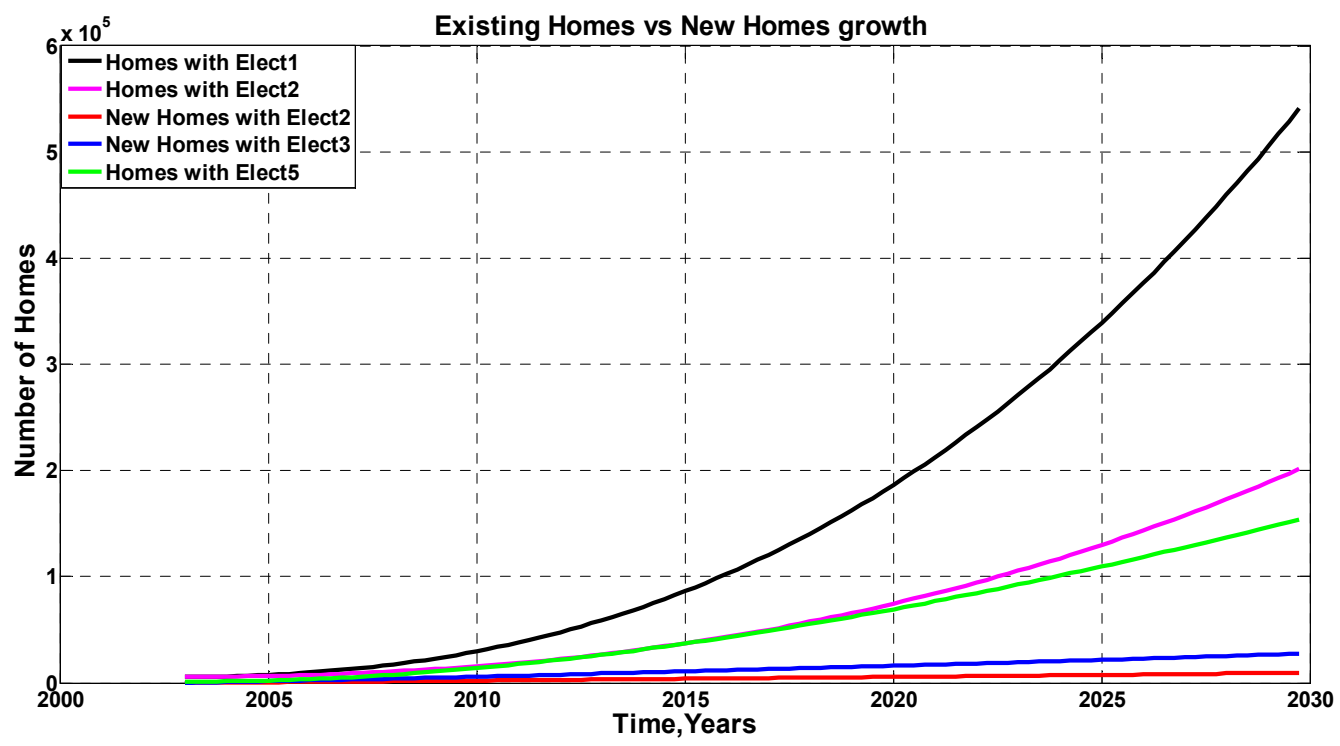

Figure 7. Trends of homes with electricity.

Table 4. Number of homes with similar electrification growth.

Scenarios Homes with similar trends

1, 3 and 4 New Homes_1 = New Homes_3 = New Homes_4

2,5 and 6 Existing Homes $2=$ New Homes $5=$ Existing homes 6

2 and 6 New Homes_2 = New Homes_6

1,3 and 4 Existing Homes_1 = Existing Homes_3= Existing Homes_4

For ease of plot and interpretation only one will be shown per category.

The solid black line shows how the existing homes increase over the 30 years period under the base case. The pink line shows on the other hand, the existing homes trend under the second scenario. The latter further shows that the total number of homes is 200,000 at the end of the period way below the 550,000 homes of the former scenario due to the constraint on the BR. The red line shows under the second scenario, the new homes with electricity supply over the entire period. The trend of the new homes with electricity supply under the third scenario is shown in blue. This curve shows an increasing number of newly constructed and electrified homes over the time frame under consideration as compared to the above case. The green line portrays the projected number of existing homes that have access to electricity supply under the fifth policy scenario. This scenario shows a slight prevalence of the number of new homes constructed over the existing homes as can be seen from the pink and green lines. As a remark, the standard of living would tremendously increase by that time.

\subsection{Gaps between Supplies and Demands}

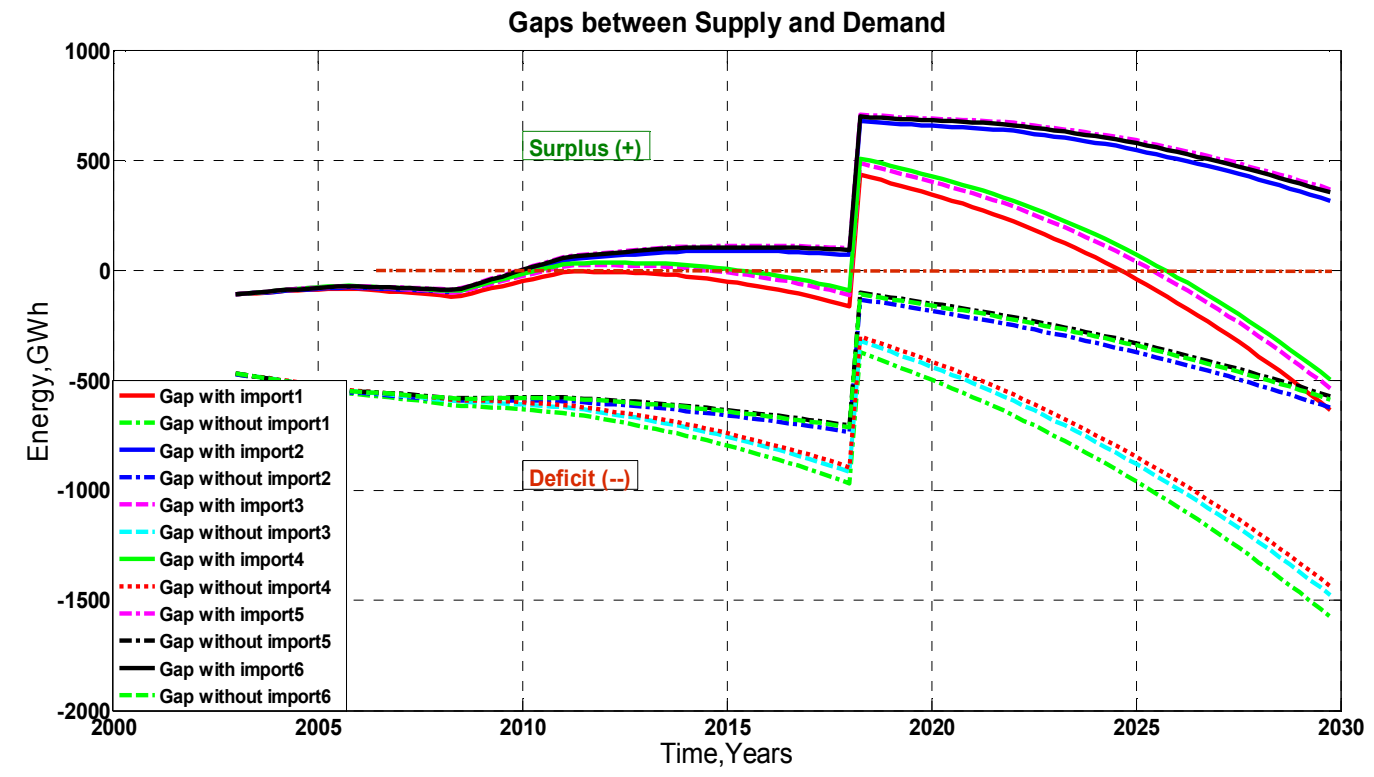

Figure 8. Projected gaps between supply and demand. 
Figure 8 shows the gaps between supply and demand with and without import under all the scenarios for comparison purposes. The dash-dotted horizontal red line shows the limit between the electrical energy surplus $(+)$ and deficit (-) over the simulation time frame.

Under the base scenario, on one hand the solid red line shows the gap including import being positive from 2018 to 2024 with a net surplus for six years. On the other hand, the dash-dotted green line shows how the gap would be without any energy import. The gap is negative all through with an increasing deficit.

The solid blue line shows the gap when the import is included; it is positive. Under the second scenario, it is clearly shown that the supply exceeds the demand over the entire simulation period starting late 2009. The economic implication is that Niger would save some money by cutting part of the budget allocated to energy import. On the other hand, the gap between the supply and demand without taking import into account is negative (deficit) through the entire period. The direct implication is that even under this scenario, electricity import although declining still plays a vital role in the energy mix.

The dashed pink and the dashed cyan lines show respectively under the third scenario the gaps between supply and demand with import and that dealing only with national efforts. In conjunction with the electricity import, Niger will be self-sufficient only for 8 years, i.e. 2018 to 2026, as can be seen from the dotted pink curve.

The solid green line under scenario four shows the gap between supply and demand when the import is being considered. The dotted red line shows the national gap comparable to that of the previous scenario. Although this scenario is better than the previous, it's still not enough to save Niger from frequent summertime power outages on the long run.

The dash-dotted pink line shows under the fifth scenario, the gap when energy import contributes to more than half of the supply. The gap is positive over the total period.
Additionally, it is important to note that the present policy is the best in terms of remedy to the power shortages that frequently occur in Niamey. It should also be noticed that without any import of electricity, the deficit is $102 \mathrm{GWh}$ over the simulation period as can be seen from the dash-dotted black line. As already stated above, implicitly under this type of scenario electricity import would continuously occupy a lesser share in the country by declining enormously.

Finally, the last scenario is the second best policy for the country as can noticed by the solid black line that shows a net positive gap. Hence, in a similar fashion the dotted green line shows that without any import of electricity, the deficit is rather $109 \mathrm{GWh}$ as compared to the previous.

In either case, the gap between the national supply and the total demand without any import is negative. This clearly indicates that as population, which is the major driver in terms of electricity consumption grows at a much faster rate, the deficit becomes even more important. Table 5 gives the summary of the various estimates under the six policy scenarios.

In 2030, the population of Niger was estimated in [58] to be 30 Million inhabitants and this model based on the current BR and DR estimates it to be approximately 28.5 Million (as given in Table 5) which is a descent approximation that helps to validate the model. The latter was exposed to the behavioral validity procedures as well.

Table 5. Summary of the estimates in 2030.

\begin{tabular}{lllll}
\hline & Population & $\begin{array}{l}\text { Demand } \\
(\mathbf{G W h})\end{array}$ & $\begin{array}{l}\text { Supply } \\
(\mathbf{G W h})\end{array}$ & $\begin{array}{l}\text { Deficit/Surplus } \\
(\mathbf{G W h})\end{array}$ \\
\hline Base & $28,021,857$ & 2420.8 & 1749.8 & -671 \\
Scenario & & & 1749.8 & +301.9 \\
Scenario 2 & $20,880,638$ & 1447.9 & 1848.7 & -572.1 \\
Scenario 3 & $28,021,857$ & 2420.8 & -529.7 \\
Scenario 4 & $28,021,857$ & 2420.8 & 1891.1 & -529.7 \\
Scenario 5 & $20,880,638$ & 1447.9 & 1801.5 & +353.6 \\
Scenario 6 & $20,880,638$ & 1447.9 & 1786.9 & +339 \\
\hline
\end{tabular}

\subsection{Carbon Footprints}

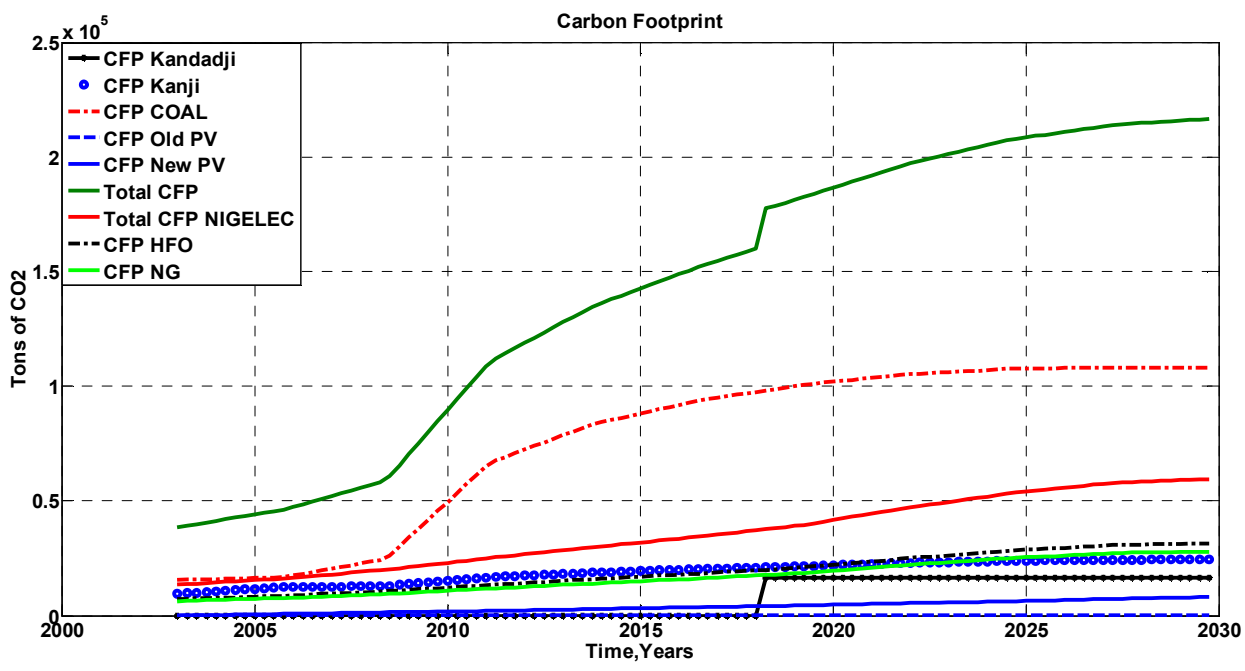

Figure 9. Past and future CFP projections 
Figure 9 depicts the various CFPs of all the generation means in Niger including the import. One major discovery to notice in terms of GHG emissions is the CFP of the utility company that is quite often ignored or underestimated in Niger. The solid fair-green line represents the NG's contribution whereas the HFO's share in shown in dashdotted black line; they both added up to the total. Hence, the total CFP of the utility company over the 20 years simulation period is illustrated by the solid red line. This quantity increases from 13,466 tons of $\mathrm{CO}_{2}$ to 59,594 tons at the end of the period. GHG emissions are a serious threat to the nation's wellbeing since the plants responsible for these rejections are all installed inside the capital city. Relocating the plants outside Niamey is one of the options at hand.

The dash-dotted red line in Fig. 9 shows the CFP of the coal fired plant installed in the northern part of the country. This plant is estimated as producing 15,590 tons of $\mathrm{CO}_{2}$ to 108,118 over the entire period. This plant is a major environmental concern for decades to come unless something is done to reduce its emissions such as a decommissioning or increasing the RE quota. The total CFP emission of Niger is shown by the solid green line. The emission is predicted to increase from 38,560 tons of $\mathrm{CO}_{2}$ to 216,900 in 2030. Note that the coal fired plant contributed to more than half of the total CFP emissions.

The various CFPs of the renewable sources are also shown in this same Fig. 9:

- The solid black line shows the CFP of the dam Kandadji initially starts at zero in 2018 and increases abruptly to 16,354 tons of $\mathrm{CO}_{2}$, then stays constant afterward.

- The annular-blue line shows the equivalent CFP of the hydro-energy import from Kanji (Nigeria). This CFP is more significant compared to the national Dam's.

- The dashed blue curve represents the CFP of the existing installed PV capacity in Niger. This emission is negligible as the whole PV installed is not so important.

- Finally, the solid blue curve shows the CFP of the additional PV that would be installed as stand-alone. It would only be connected to the grid during summertime to prevent power outages.

\section{Conclusion and Policy Implications}

This paper shows that system dynamics, SD, is a valuable approach in estimating long-term electricity supply and demand. The study used SD modeling to estimate the total electricity demand in Niger from the present to 2030.The population, the major economic sectors, and per capita electricity consumption data were utilized in the study. Under the various policy scenarios adopted in this study, not all of them are applicable in real life (e.g. cutting the birth-rate in half) and that confirms the essence and the flexibility of utilizing simulation rather than real life experience. Hence, the results of the study clearly indicate the following:

- The population in Niger, under the current birth-rate, will be close to 30 million in 2030. Through the per capita energy consumption, this will drive the future energy trends resulting in an increase at an alarming rate.

- Niger will continue to import electricity from Nigeria even after the completion of Kandadji dam in the horizon of 2018.

- The study reveals that Niamey, and the surrounding vicinity, will only be self-sufficient in terms of electricity for eight years after the completion of the dam.

- The electricity imported from Nigeria will continue its decline and then rise after 2026.

- In the long run, Niger would only be able to reach its energy independence by either:

- reducing its population growth rate or

- finding additional energy sources.

- The results also showed that the various CFPs were exponentially compounding. They may not only affect the inhabitants' health in Niamey, but may also continue to damage the fragile eco-system around the city.

- Finally, this study will help decision makers maintain a balance between supply and demand while strategically facilitating the management of the utility company.

\section{Abbreviations}

$\begin{array}{ll}\text { ARDL } & \text { Autoregressive Distributed Lag } \\ \text { BR } & \text { Birth rate } \\ \text { CDC } & \text { Cri De Cigogne } \\ \text { CFP } & \text { Carbon Footprint } \\ \text { CNEDD } & \text { Conseil National de l'Environnement pour } \\ \text { CODDAE } & \text { un Développement Durable } \\ \text { CUN } & \text { Collectif de Défense du Droit à l'Energie } \\ \text { DR } & \text { Death Rate } \\ \text { GHG } & \text { Greenhouse Gases } \\ \text { GUI } & \text { Graphical User Interface } \\ \text { GWh } & \text { Gigawatt-hour } \\ \text { HFO } & \text { Heavy Fueled Oil } \\ \text { INS } & \text { Institut National de la Statistique } \\ \text { NG } & \text { Natural Gas } \\ \text { NIGELEC } & \text { Niger Electricité } \\ \text { RE } & \text { Renewable Energy } \\ \text { RNI } & \text { Rapport National d'Investissement } \\ \text { SCB } & \text { Supply Curve Bidding } \\ \text { SD } & \text { System Dynamics } \\ & \end{array}$

\section{Acknowledgements}

- International Institution of Education (IIE) through the Fulbright program under the grant number: 15101134 (Period: Fall 2010-Spring 2012)

- NV Energy through the Urban Sustainability Initiatives' grant (Period: Fall 2012-Fall 2013). 


\section{References}

[1] W. Li, Z. Zhang, and M. Wei, "Forecast on Hebei energy consumption based on system dynamics," Cross Strait QuadRegional Radio ..., pp. 1541-1543, 2011.

[2] S. L. Koh and Y. S. Lim, "Meeting energy demand in a developing economy without damaging the environment- $\mathrm{A}$ case study in Sabah, Malaysia, from technical, environmental and economic perspectives," Energy Policy, vol. 38, no. 8, pp. 4719-4728, Aug. 2010.

[3] C. D. C. Cdc, "Bilan énergétique et perspectives pour une politique énergétique ambitieuse au Niger," no. Cdc, 2009.

[4] Institut National de la Statistique (INS) du Nigerhttp://www.stat-niger.org/statistique/[Accessed December 5, 2013].

[5] Finance, H. \& Africa, I.N., 2011. YEARBOOK. Centre for Affordable Housing Finance in Africa a division of the FinMark Trust, (September).

[6] Collectif de défense du droit à l'énergie (Coddae), $\mathrm{http}: / /$ www.energiesosfutur.org/wpcontent/uploads/2010/09/Lettre_situation_\%C3\%A9lectrique Niger_coddae_dae.pdf [Accessed December 4, 2013].

[7] National utility company, Niger (NIGELEC, Niger): http://www.nigelec.ne[Accessed November 10, 2013].

[8] http://www.ne.undp.org/[Accessed November 10, 2013].

[9] H. Amusa, K. Amusa, and R. Mabugu, "Aggregate demand for electricity in South Africa: An analysis using the bounds testing approach to cointegration \$," Energy Policy, vol. 37, no. 10, pp. 4167-4175, 2013.

[10] A. Boogert and D. Dupont, "When supply meets demand: the case of hourly spot electricity prices," Power Syst. IEEE Trans., vol. 23, no. 2, pp. 389-398, 2008.

[11] M. L. Baughman and P. L. Joskow, "The Future Outlook for the U.S. Electricity Supply and Demand," Proc. IEEE, vol. 65, no. $4,1977$.

[12] T. Tusar, E. Dovgan, and B. Filipic, "Evolutionary scheduling of flexible offers for balancing electricity supply and demand," Evol. Comput. (CEC), ..., pp. 10-15, 2012.

[13] Q. Zhang, K. N. Ishihara, B. C. Mclellan, and T. Tezuka, "Scenario analysis on future electricity supply and demand in Japan," Energy, vol. 38, no. 1, pp. 376-385, 2012.

[14] O. Alnatheer, "The Potential contribution of renewable energy to electricity supply in Saudi Arabia," Energy Policy, vol. 33, pp. 2298-2312, 2005.

[15] G. Heinrich, M. Howells, L. Basson, and J. Petrie, "Electricity supply industry modelling for multiple objectives under demand growth uncertainty," Energy, vol. 32, pp. 2210-2229, 2007.

[16] S. Y. Al-agtash, "Supply curve bidding of electricity in constrained power networks q," Energy, vol. 35, no. 7, pp. 2886-2892, 2010.

[17] P. K. Toan, N. Minh, and N. H. Dieu, "Energy supply, demand, and policy in Viet Nam , with future projections," Energy Policy, vol. 39, no. 11, pp. 6814-6826, 2011.
[18] De Vita, G., Endresen, K., Hunt, L.C., 2006, An empirical analysis of energy demand in Namibia, Energy Policy 34, $3447-3463$

[19] Ziramba, E. 2008, "The demand for residential electricity in South Africa", Energy Policy, vol. 36, no. 9, pp. 3460-3466.

[20] P. Kofi, W. Bekoe, S. Kutri, and K. Akoena, "Modelling aggregate domestic electricity demand in Ghana: An autoregressive distributed lag bounds cointegration approach," Energy Policy, vol. 42, pp. 530-537, 2012.

[21] Naill, R. F. (1973). The Discovery Life Cycle of a Finite Resource: a Case Study of U.S. Natural Gas. in: D.L. Meadows (Ed.), Toward Global Equilibrium: Collected Papers, MIT Press, Cambridge, MA.

[22] J. D. Sterman, "John D. Sterman, The Energy Transition and Economy; A System Dynamics Approach, 1981." Unpublished work, 1981.

[23] E. Suryani, S.-Y. Chou, R. Hartono, and C.-H. Chen, "Demand scenario analysis and planned capacity expansion: A system dynamics framework," Simul. Model. Pract. Theory, vol. 18, no. 6, pp. 732-751, Jun. 2010.

[24] S. C. Bhattacharyya and G. R. Timilsina, "Modelling energy demand of developing countries: Are the specific features adequately captured?," Energy Policy, vol. 38, no. 4, pp. 1979-1990, 2010.

[25] Rahn J. 1981. A system dynamics model for long range electric utility planning: implementation experience. Dynamica 7:32-35.

[26] A. Ford, J. Wright, and F. Prize, "System Dynamics and the Electric Power Industry,” vol. 13, no. 1, pp. 57-85, 1997.

[27] H. Qudrat-Ullah, "Understanding the dynamics of electricity generation capacity in Canada: A system dynamics approach," Energy, pp. 285-294, 2013.

[28] H. Qudrat-Ullah and P. I. Davidsen, "Understanding the dynamics of electricity supply, resources and pollution: Pakistan's case," Energy, vol. 26, no. 6, pp. 595-606, Jun. 2001.

[29] Y. Prambudia and M. Nakano, "Scenario Analysis of Indonesia 's Energy Security by using a System-Dynamics Approach," pp. 899-904, 2010.

[30] S. A. Akhwanzada and M. Tahar, "Long-term Electricity Forecasting: A System Dynamics Approach,” vol. 33, pp. 116-119, 2012.

[31] S. A. Akhwanzada and R. M. Tahar, "Strategic Forecasting of Electricity Demand Using System Dynamics Approach," vol. 3, no. 4, pp. 328-333, 2012.

[32] UNDP, "Rapport sur le développement humain 2013," Аnnu. Rep., 2013; [Accessed November 10, 2013].

[33] Ahmad S, Simonovic SP (2000). "System dynamics modeling of reservoir operations for flood management." J Comput Civ Eng 14(3):190-198.

[34] Dawadi S and Ahmad S (2013). "Evaluating the Impact of Demand-Side Management on Water Resources under Changing Climatic Conditions and Increasing Population." Journal of Environmental Management, 114, 261-275. 
[35] Qaiser K, Ahmad S, Johnson W, Batista J (2013). "Evaluating Water Conservation and Reuse Policies using a Dynamic Water Balance Model." Environmental Management, 51(2): 449-458.

[36] Ahmad S, Simonovic SP (2004). "Spatial system dynamics: new approach for simulation of water resources systems." J Comput Civ Eng 18(4):331-340.

[37] Ahmad S, Simonovic SP (2006). "An intelligent decision support system for management of floods." Water Resour Manag, 20(3): 391-410.

[38] Sterman, J.D., 2000. Business Dynamics: Systems Thinking and Modeling for a Complex World. McGraw-Hill, NY.

[39] Mirchi A, Madani K, Watkins D, Ahmad S. 2012. Synthesis of system dynamics tools for holistic conceptualization of water resources problems. Water Resources Management 26 (9), 2421-2442.

[40] R. Rehan, M. Knight, C. Haas, and A. Unger, “Application of system dynamics for developing financially self-sustaining management policies for water and wastewater systems," Water Res., pp. 1-14, 2011.

[41] Dawadi S and Ahmad S (2012). "Changing Climatic Conditions in the Colorado River Basin: Implications for Water Resources Management.” Journal of Hydrology, 430 431: $127-141$.

[42] Qaiser K, Ahmad S, Johnson W, Batista J (2011). "Evaluating the impact of water conservation on fate of outdoor water use: A study in an arid region." J Environ Manage 92(8): 20612068.

[43] Shrestha E, Ahmad S, Johnson W, Shreshta P, Batista JR (2011). "Carbon Footprint of Water Conveyance versus Desalination as Alternatives to Expand Water Supply." Desalination 280 (1-3):33-43.

[44] Venkatesan AK, Ahmad S, Johnson W, Batista JR (2011a) "Salinity Reduction and Energy Conservation in Direct and Indirect Potable Water Reuse". Desalination 272(1-3):120-127.

[45] Shrestha, E., Ahmad, S., Johnson, W., and Batista, J. (2012). "The carbon footprint of water management policy options." Energy Policy, 42, 201-212.

[46] Venkatesan AK, Ahmad S, Johnson W, Batista JR (2011b). "System Dynamics Model to Forecast Salinity Load to the Colorado River Due to Urbanization within the Las Vegas Valley”. Sci Total Environ 409(13): 2616-2625.
[47] Ahmad S and Prashar D (2010), Evaluating Municipal Water Conservation Policies Using a Dynamic Simulation Model, Water Resources Management 24(13): 3371-3395.

[48] Wu G, Li L, Ahmad S, Chen X, Pan X. 2013. A Dynamic Model for Vulnerability Assessment of Regional Water Resources in Arid Areas: A Case Study of Bayingolin, China, Water Resources Management, 27(8): 3085-3101.

[49] Fhttp://www.iseesystems.com/ [Accessed November 2013].

[50] Energy report, Niger: https://estore.enerdata.net/fr/rapportenergie/niger-rapport-energie-et-donnee.html [Accessed November 16, 2013].

[51] Conférence de haut niveau sur : L'eau pour l'agriculture et l'énergie en Afrique: les défis du changement climatique Syrte, Jamahiriya Arabe Libyenne, 15-17 décembre 2008 ; Rapport National d'Investissement, Niger (RNI, 2008) [Accessed November 13, 2013].

[52] Conseil National de l'Environnement pour un Développement Durable Secrétariat Exécutif, Seconde Communication Nationale du Niger sur les Changements Climatiques, 2009 (CNEDD) [Accessed November 18, 2013].

[53] http://www.snvworld.org/en/countries/niger, November 18, 2013]

[Accessed

[54] Ali Kerem Saysel et al., "Exploring the options for carbon dioxide mitigation in Turkish electric power industry: System dynamics approach," Energy Policy, 2013.

[55] H. Dong, Y. Geng, F. Xi, and T. Fujita, "Carbon footprint evaluation at industrial park level: A hybrid life cycle assessment approach," Energy Policy, vol. 57, pp. 298-307, Jun. 2013.

[56] Y. Kajikawa, J. Yoshikawa, Y. Takeda, and K. Matsushima, "Tracking emerging technologies in energy research: Toward a roadmap for sustainable energy," Technol. Forecast. Soc. Change, vol. 75, no. 6, pp. 771-782, Jul. 2008.

[57] World Nuclear Association (WNA) Report, July 2011. http://www.world-

nuclear.org/uploadedFiles/org/WNA/Publications/Working_Gr oup_Reports/comparison_of_lifecycle.pdf [Accessed November 2013].

[58] Issaka Maga H., Guengant Jean-Pierre, Population et Société au Niger, Bulletin d'analyse des questions de population pour le développement, $\mathrm{N}^{\circ} 01$ du février 2012 [Accessed December $5,2013]$. 